2006-1753: GENDER PERFORMANCE ASSESSMENT OF UNIQUE HANDS-ON INQUIRY BASED ENGINEERING LESSONS IN SECONDARY MATHEMATICS AND SCIENCE CLASSROOMS

Anant Kukreti, University of Cincinnati

James Allen, University of Cincinnati

Michelle Daniel, University of Cincinnati 


\section{Gender Performance Assessment of Unique Hands-On Inquiry-Based Engineering Lessons In Secondary Mathematics and Science Classrooms}

The University of Cincinnati's National Science Foundation (NSF) Graduate K-12 Fellow's grant, Project STEP - Science and Technology Enhancement Program, was created to train graduate students so that they bring their technical background and expertise into the classroom guided by current experienced teachers so that students can be effectively engaged and can relate the science, technology, engineering, and mathematics (STEM) knowledge they learn to the world they live in. Eight research fellows were trained to bring their engineering experiences, both academic and professional, to area classrooms through the creation of unique hands-on inquiry based learning activities. Each of the STEP fellows work together with an assigned mathematics or science teacher to develop these unique hands-on activities in order to align them to state academic standards. The fellows then present these lessons to each of their classes in an effort to gain practical secondary teaching experience. In addition, the fellows also perform all grading and assessment of these activities. On occasion, the teachers will also administer these lessons to help demonstrate alternative teaching and classroom management techniques. However, in this study, each lesson for which the data is presented was taught by a STEP fellow. Project STEP believes that through effectively demonstrating the relevance of mathematics and science topics through real-world issues and current community events, a stronger student affinity towards these subjects can be achieved. This paper explores the development of student attitudes towards math and science topics on a gender basis. Seven classrooms of $11^{\text {th }}$ grade math and science students were used in this study to provide quantitative and qualitative data to support the authors' beliefs.

According to the National Assessment of Educational Progress (NAEP), the percentage of male and female students enrolling in science and mathematical subject area has increased significantly over the past two decades. In 1980, the media press coverage of Benbow and Stanley's ${ }^{2}$ study of mathematically gifted youth suggested that boys' higher scores on PSATMath were attributable to innate biological differences. At the time, this statement was controversial, implying that there was an insurmountable barrier to high performance of women in these areas. This idea had its foundation in the long-standing belief that male and female students perform differently in mathematics and science subject areas. Kahle ${ }^{1}$ states that "gender differences in science and achievement vary in direction and degree across various racial/ethnic groups." Kahle's research indicated that African-American girls out-achieved the boys in science, both on physical science and biological test items. However, a stronger and more positive relationship between attitudes and achievement in science was found for boys, compared with girls. While there is evidence that male students are, by nature, typically attracted to more exciting and destructive subject content, female students demonstrate an additional interest in environmental and social issues.

Kondrick $^{3}$ interviewed physical science, science, technology engineering and mathematics (PSTEM) career women who expressed the importance of supportive family, friends, professional organizations and mentors in achieving their career objectives. Kondrick ${ }^{4}$ later states that "the under-representation of women in physical science, technology, engineering, 
and mathematics (PSTEM) career fields is a persistent problem." In her review, she states that confidence issues were found to be a barrier while goal-orientation was an asset. In addition, negative environments were offset by positive social support networks. While female students are definitely capable of high performance in mathematic and science subject areas, the recognition by educators of the existence of specific gender-based areas of engagement can be used to create lessons and grouping situations that can be mutually beneficial to both male and female students. These differences create unique, gender specific learning styles in each student. By taking advantage of these unique styles, educators should be able to improve the learning capabilities of all participating students, regardless of gender.

During the Fall of 2005, four unique activities were developed relating real-world issues to $11^{\text {th }}$ grade Algebra II and Environmental Science students. The urban school in which these lessons were implemented is located within Cincinnati and is comprised of predominately minority students from lower to middle income families. This particular institution employs a Paideia teaching philosophy. The lessons created by Project STEP fellows attempted to adhere to this philosophy by providing students opportunities to explore and reflect on the activities presented. To aid the students in their quest for self-learning, class work and projects were often conducted in a group style format.

The following activities were presented between September and December of 2005:

\begin{tabular}{|c|c|}
\hline Environmental Science & Algebra 2 \\
\hline The Water Recycler $(T W R)$ & Cincinnati Evacuation Planning (CEP) \\
\hline The Bengal's Oily Mess $(B O M)$ & City Planning $(C P)$ \\
\hline
\end{tabular}

Each lesson was presented to approximately seventy-five students in multiple classes within the same school; a large number of whom participated in both the science and mathematics activities. These lessons were established with a secondary objective of investigating the effectiveness of group style and lesson format on the overall performance of the students. In the first lesson, Cincinnati Evacuation Planning (CEP), students were not allowed to select their group, but rather were assigned to work with their immediately adjacent neighbor. The Water Recycler (TWR) lesson did not incorporate student groups, but instead relied on individual student work and class discussions. The City Planning (CP) activity involved assigned teams with a competition element. Finally, the Bengal's Oily Mess (BOM) allowed student-choice groups. In-depth descriptions of these four activities will be discussed in the remainder of this paper.

Lesson Name: Cincinnati Evacuation Planning

Class: $11^{\text {th }}$ grade Algebra II

Duration: (4) 50 minute class periods

Gender Breakdown: $42 \%$ male, $58 \%$ female

Grouping Type: neighbor assigned teams

Activity Type: independent / collaborative / noncompetitive

Standards Addressed:

Mathematics

Number, Number Sense and Operations Standard 


\section{Measurement Standard \\ Geometry and Spatial Sense Standard \\ Patterns, Functions and Algebra Standard \\ Data Analysis and Probability Standard}

The Cincinnati Evacuation Planning lesson was presented to an $11^{\text {th }}$ grade Algebra II class in late September of 2005. This lesson involved a combination of teacher driven lectures (didactic), class discussions, and independent yet collaborative problem solving activities.

The first day of the activity was spent discussing different types of disasters and how civil engineers plan for such disasters during project design. The discussion of disaster-type was divided into human-caused and natural disasters. A discussion of warning time, length, and duration of a disaster's after effects was conducted through student use of prior knowledge as well as recent news events, specifically Hurricane Katrina. During the hands-on problem solving portion of this activity, students were assigned partners to work collaboratively on the evacuation planning assignment. Students were supplied with a map of downtown Cincinnati and were presented with a disaster scenario. The scenario consisted of a fictional tornado sighting at a known distance from a downtown area where they (the students) were located. The scenario detailed how a storm of a specific size and velocity was heading for their location at a specified speed. Students were asked to perform algebraic calculations to determine how long it would take the tornado to reach their location. The problem description detailed several alternative methods of escape such as travel by car, walking, or bus and their equivalent rates of speed for escape. Students were asked to identify their locations and assess the area that the storm would impact on their maps. Using this information, students chose a method of escape, and determined if their path would allow them to reach safety (defined as being outside of the path and impact area). Upon conclusion of the calculations, students were asked several questions concerning the students' cognitive reasoning for their escape route selection, as well as their means of escape. Several free-form qualitative questions were included in the exercise to allow students to describe the scene of the scenario in their own words. These questions were then surveyed for the use of key words and emotions.

The discussion of Hurricane Katrina and its widely publicized impact on New Orleans had a tremendous impact on the engagement of students. The students were very interested in how the storm was formed, and the various infrastructure issues that led to the severity of the disaster. The Cincinnati Evacuation Planning activity and its connection with Hurricane Katrina were also significant to the students because several new students had recently relocated from New Orleans to their school. The students had taken up a collection of dollar bills to help provide for the new students and their families. Several female students in the Algebra II class were especially eager to raise money for them, repeatedly asking the instructors to contribute. During class discussions, male students were eager to discuss the level of damage and duration of specific disaster examples while the female students seemed more interested in discussing the impact on personal property (people's homes specifically). Throughout this Algebra II activity, the instructor observed that male students were found to have an increased level of interest and engagement during the discussion of natural and human-caused disasters while female students appeared to take more interest in the activities related to issues of human life. 
During this exercise, students were asked free-response, qualitative questions regarding their observations and interpretations of the scenario. Figure 1 displays the results to the questions based on responses in four categories: attention to emotions, children, people, and facts. From these questions, percentages of each gender that provided a response within each category are displayed for each class. It can be seen in Figure 1 that female responses showed a marked increase in awareness of emotions, children, and people. Conversely, over $92 \%$ of male students reported the facts of the scenario which was the highest percentage of student response across all classes for this exercise. Through this assessment, it was found that $13-19 \%$ of responses mention babies and children, all of which were exclusively written by females.

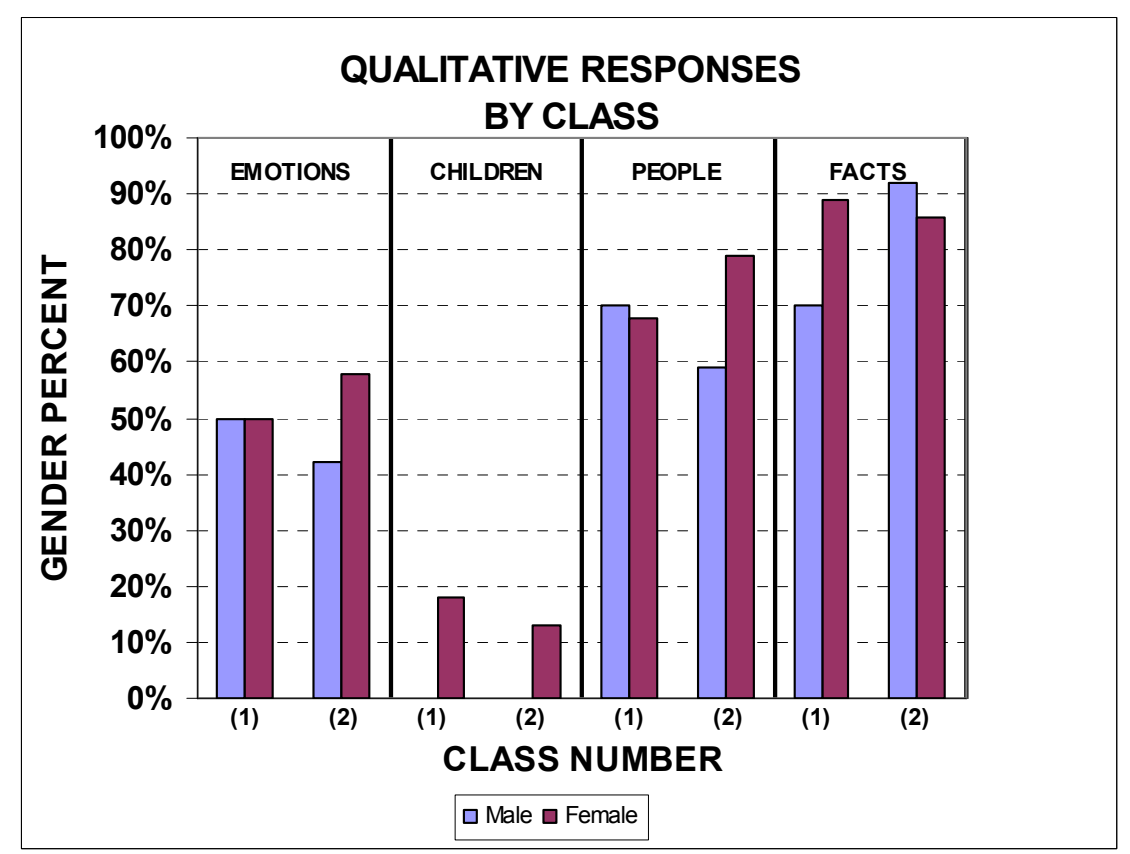

Figure 1: Qualitative Response questions for Cincinnati Evacuation Planning.

Quantitative results from this exercise were determined from the hands-on portion of the activity. Students were evaluated in four specific skill areas: mathematical computation, scenario observations, mapping exercises, and overall performance. Figure 2 illustrates the performance in each category of each gender in each class for the entire activity. As shown, in all but one class, female students achieved the highest scores in the four skill areas, including achieving the highest overall average by almost two points. It is the author's belief that female students were more focused on completing the assignment and, as a result, maintained a sustained interest in the subject area.

Finally, the effects of group makeup (all-male, all-female, and mixed gender) were determined. Figure 3 combines the gender performance averages from Figure 2 with group gender makeup data. In this figure, it can be seen that the all-male student groups continuously outscored the all-female and mixed-groups (both male and female students) in the mathematics subject area. However, in the mapping category and overall grades, the mixed-groups outperformed the all-male groups. In the case of overall performance, mixed groups scored 2-5 points higher than the all-male groups. This trend is highly encouraging that perhaps the mix of male and female students helped to improve the overall performance of the individual students. 
While male students demonstrated higher scores in the mathematics categories, female students outperformed the males on mapping exercises.

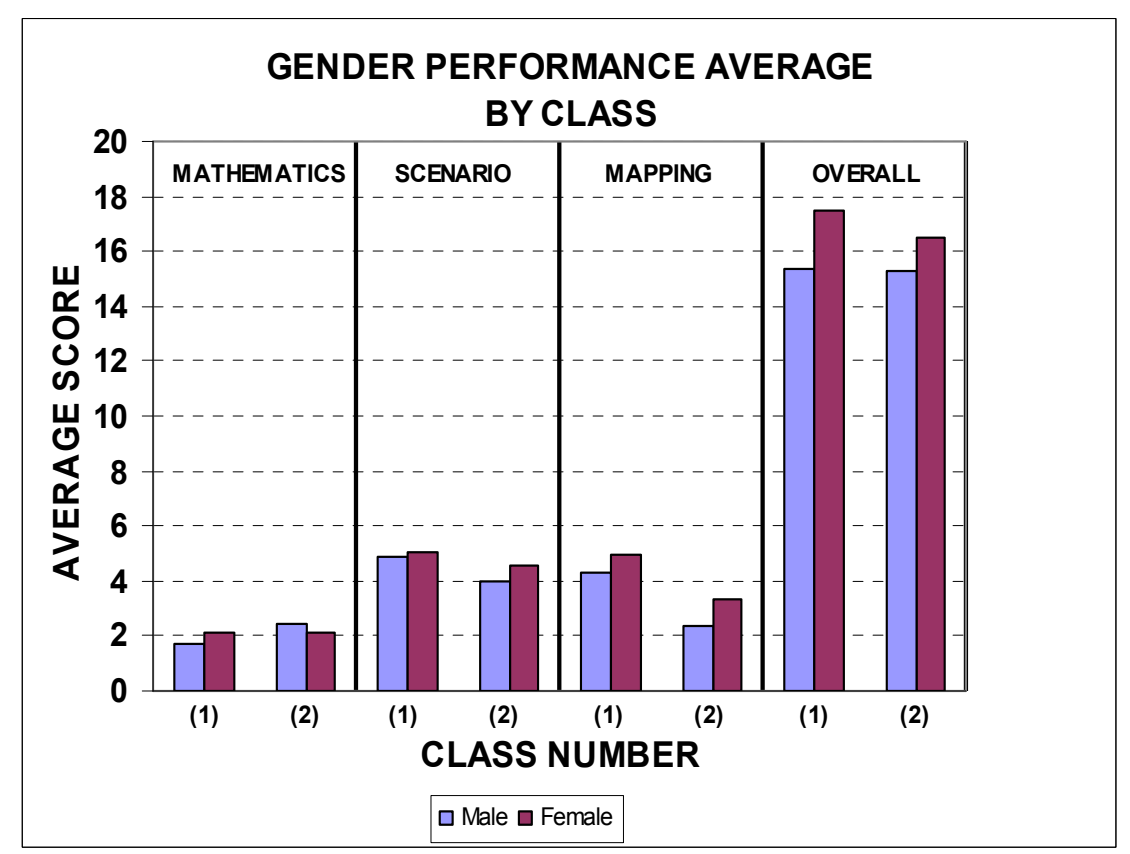

Figure 2: Gender Performance Average by Bell for Cincinnati Evacuation Planning.

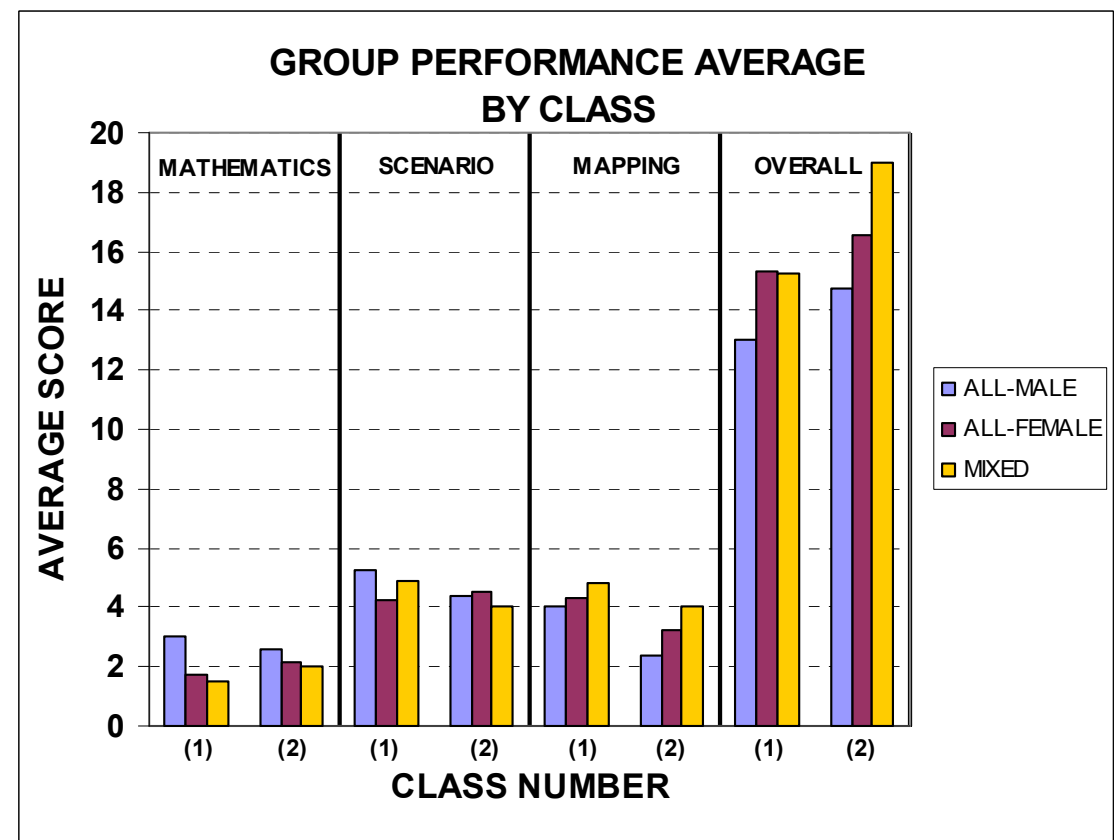

Figure 3: Group Performance Average by Bell for Cincinnati Evacuation Planning.

Lesson Name: The Water Recycler (TWR)

Class: $11^{\text {th }}$ Grade Environmental Science

Duration: (3) 50 minute class periods 
Gender Breakdown: $45 \%$ male, 55\% female

Grouping Type: individual student work and small groups

Activity Type: teacher-driven class discussion

Standards Addressed:

$\underline{\text { Science }}$

Earth and Space Science

Life Sciences

Physical Science

Science and Technology

Scientific Inquiry

The Water Recycler lesson was presented to four $11^{\text {th }}$ grade Environmental Science classes in October 2005. The Water Recycler was a teacher-centered lesson that revolved around class discussion, note-taking, calculations, power point presentations, and demonstrations. Although this lesson was didactic in nature, the students were taught the lesson content in a realworld context with visuals, examples and demonstrations to create a more engaging atmosphere.

TWR was introduced by using student's prior knowledge, more specifically information about their personal water usage. The activity was further developed through the use of a teacher-led demonstration in which the students visually observed and then drew the distribution of water on Earth. Students then practiced their mathematical expertise by completing water usage calculations. Students in these science classes repeatedly expressed frustration with having to perform mathematical calculations in their science classes. The next day of the lesson involved the use of slides to convey the information that that the students needed to know about the water cycle. Student took notes on the 6 main components of the water cycle during the activity. In addition to the power-point, there were sublimation demonstrations (screaming ice, blowing up a balloon, and smoking water). It was observed that students were very interested and engaged in discussion about the activities of sublimation. The final day of the lesson began with a hands-on activity called "The Penny Puddle" in which students explored various properties of water including surface tension. The remainder of the lesson was didactic, in which the students were required to copy down relevant information onto their guided notes sheet and then independently study the terms and concepts on their own.

Many strategies were used in this lesson to enhance the learning of students. One strategy used in this lesson was graphic organizers. Hands-on demonstrations (the penny puddle) as well as teacher led demonstrations (sublimation/dry ice) were incorporated into the lesson to make the subject matter more interesting and interactive. Reading activities were incorporated into the lesson as well as simple mathematics problems. Because of the didactic nature of the lesson, the lesson was broken into manageable chunks that involved variety in instruction. Questioning techniques and student comments were used to guide the discussion of the content.

From video observations, it was seen that, in general, female students answered more questions than the male students. One female student in particular answered several questions about the Water Cycle and asked very inquisitive questions ("Is pumice like the rock in an aquifer?") Another observation taken from the video illustrated that female students were very concerned about what they needed to write on their guided note sheets. If exact information was 
not highlighted on a slide, the female students were very concerned with what exactly needed to be written down.

Figure 4 shows the average scores for each gender across all classes. As shown in this figure, female students outperformed the male students on the overall project, although the difference between genders for this didactic activity type was minimal.

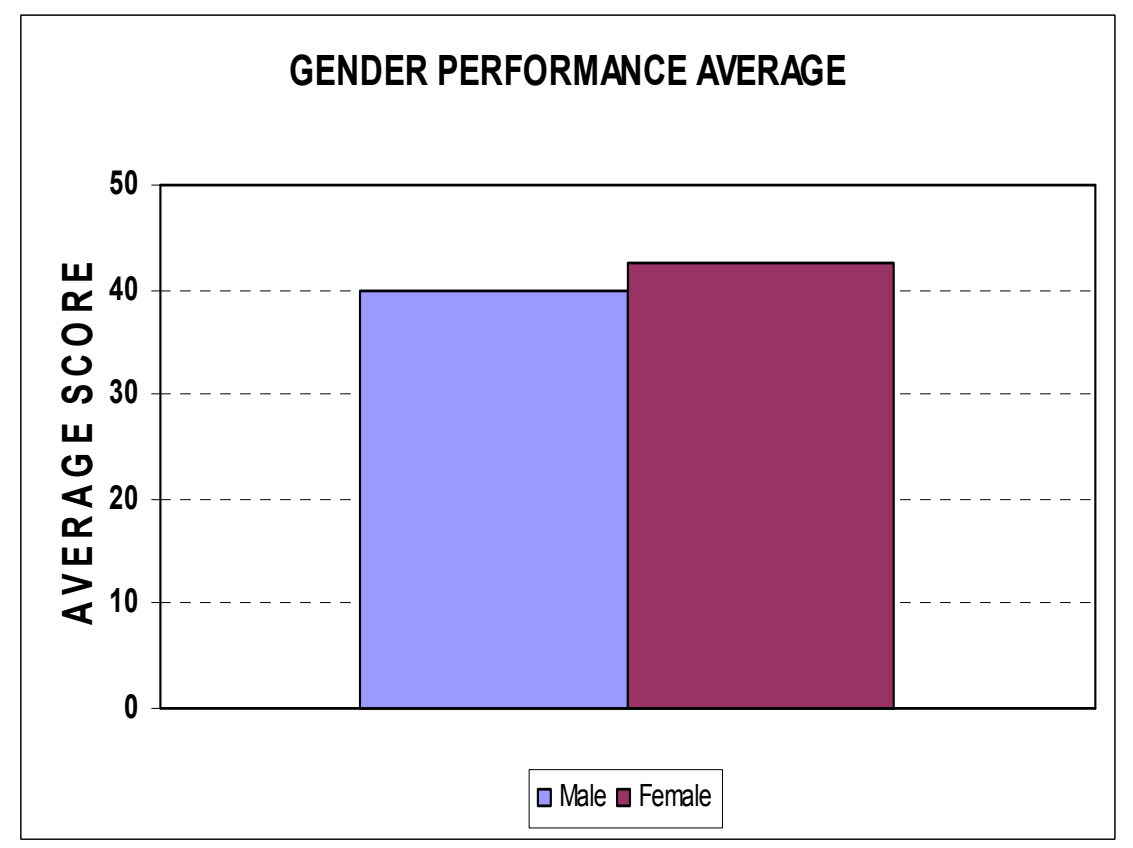

Figure 4: Group Performance Average for The Water Recycler (TWR).

\section{Lesson Name: City Planning}

Class: $11^{\text {th }}$ grade Algebra II

Duration: (3) 50 minute class periods

Gender Breakdown: $42 \%$ male, $58 \%$ female

Grouping Type: neighbor assigned teams

Activity Type: teamwork / competitive

Standards Addressed:

Mathematics

Number, Number Sense and Operations Standard

Measurement Standard

Geometry and Spatial Sense Standard

Patterns, Functions and Algebra Standard

Data Analysis and Probability Standard

City Planning was originally delivered in early November 2005. This lesson involved familiarizing the students with various aspects of city planning as well as involving them in a mock City Planning Board meeting. The beginning of the lesson was designed as a dialog between the instructor and the students about what they felt were important features of a city. Aside from basic resources such as safety, schools, employment, and housing, they were asked to generate lists of items that they felt made a community a better place to live. Each group was 
asked to brainstorm a list of amenities (facilities, services, etc.), and then select the top three that they felt were most important from their list. Each group then chose one item to be put onto a referendum list that would be voted on by all groups. The students were eager to submit ideas, and friendly debates developed as certain groups were pushing for their desired amenity. This discussion was intended to give a representative idea of how ideas are chosen, and how people become attached to amenities that they believe are important. In both classes, male students were interested in bringing entertainment based features to their city in the form of sports teams and nightclubs. Conversely, several females strongly expressed the importance of social amenities such as daycare facilities and welfare and employment agencies. The discussion that ensued was self-sustaining, requiring only minimal guidance and occasional redirection by the instructor.

During the lesson, a trivia game took place that asked students questions about such things as population history, population growth, and future population sizes using the growth prediction model. These trivia questions involved science, history and mathematics knowledge. Rewards were presented to the student supplying the quickest, correct response for each question. After the first question was asked and rewarded, the instructor successfully acquired the complete and undivided attention of every student in the class, regardless of gender. In fact, regulation of classroom behavior was inherently taken over by the students. Even students who normally seemed uninterested were listening and participating, hoping to win one of the trivia prizes.

The final portion of this activity was designed as a competition between the student groups, asking them to pretend that they were bidders proposing a layout plan to the Mayor. Each group was required to design a city layout that met pre-specified requirements and then complete several calculations for their city layout including the estimated costs, population predictions, and the potential tax revenue generation. To further increase the realism of this lesson, several zoning restrictions we created to guide the placement of the residential zones in relation to schools and safety. With the exception of the zoning restrictions, the students' city layout designs were completely open ended. This allowed the students to be creative and resulted in a wide variety of different city layouts.

As with the CEP exercise, students were evaluated in four specific skill areas: mathematical computation, scenario observations, mapping exercises, and over performance. The average scores of each gender in each class are shown in Figure 5. This figure shows that female students performed better or as-well as their male counterparts in this activity. In the mapping and scenario portions of this activity, females scored nearly twice as well as the male students in one of the classes observed. Figure 6 illustrates the averages of the students when broken out into group type. In the mapping and overall areas, mixed groups outperformed the all-male groups. 


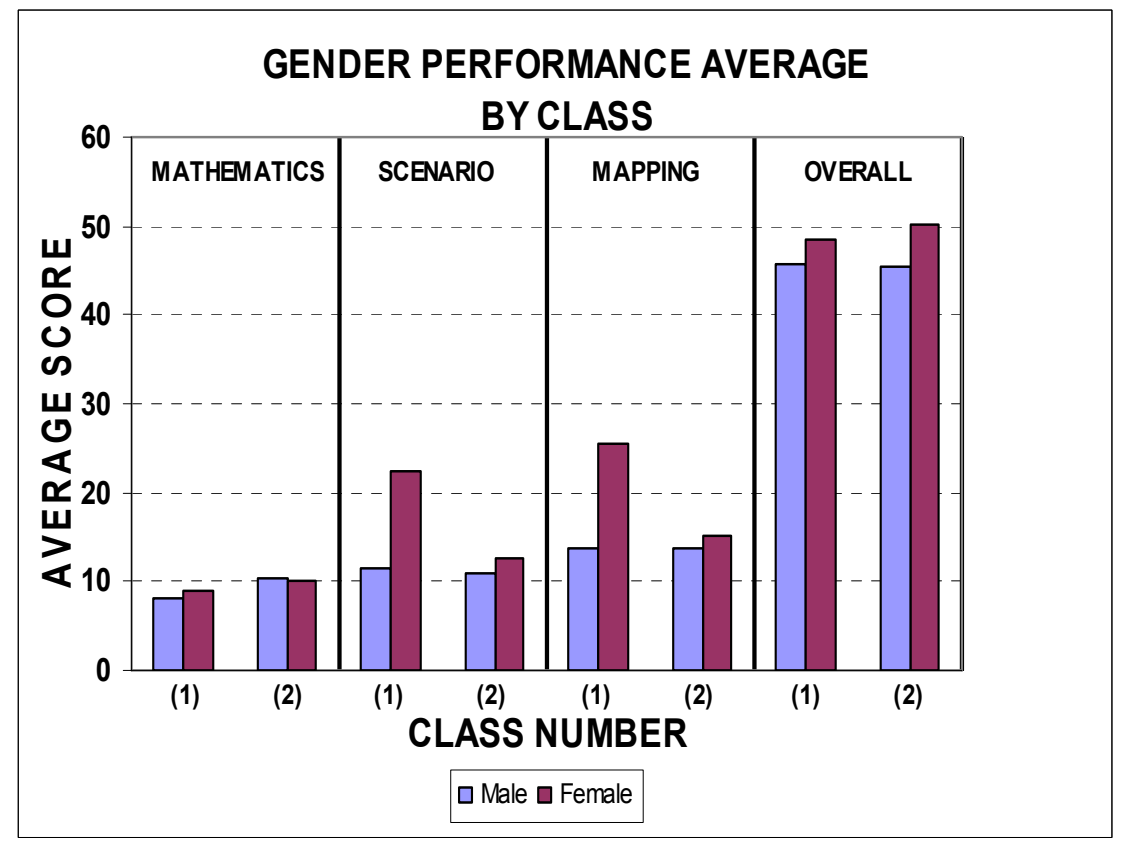

Figure 5: Gender Performance Average by Bell for City Planning

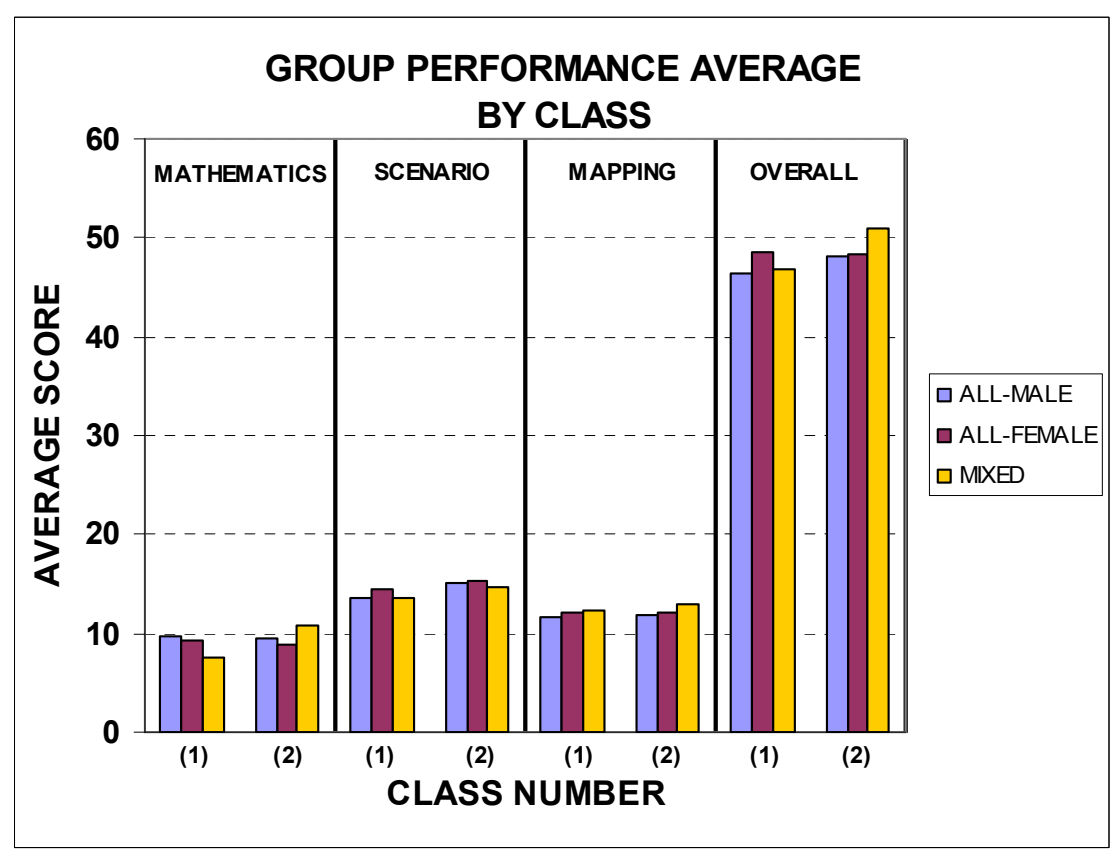

Figure 6: Gender Performance Average by Bell for City Planning

Lesson Name: The Bengal's Oily Mess

Class: $11^{\text {th }}$ Grade Environmental Science

Gender Breakdown: $45 \%$ male, 55\% female

Grouping Type: student choice (3-5 students)

Activity Type: groups-teamwork, competition

Standards Addressed:

Science 


\section{Earth and Space Science}

Scientific Ways of Knowing

Technology

\section{Technology and Society Interaction}

Design

The Bengal's Oily Mess lesson was presented to three $11^{\text {th }}$ grade Environmental Science classes in October 2005. The activity was introduced through the use of the "Water Pollution Map," a concept map that focused on water pollution and its relationship to the Ohio River. Following the conclusion of this teacher-led class discussion, The Bengal's Oily Mess scenario was introduced. Students were divided into student-selected groups of three to five pupils for the first part of the oil removal activity. During the first stages of this part of the activity, student groups experimented with clean-up materials such as cotton balls, feathers, straws, sand, pebbles, cornstarch, powdered sugar, cardboard, paper towels in order to see how they would react with oil. A secondary goal was for students to observe the effectiveness of each material as an oil removing agent. Students completed a data table that recorded the results of their material experimentation so it could be used the following day for the design of their actual oil removal plan. Student groups were very involved during this hands-on portion of the activity. It was difficult to get the students started, but once they began experimenting with the materials, oil, and water, it was difficult to get them to clean up and go to their next class.

During the second part of the activity, students worked specifically on designing an oil removal plan. It was a struggle for many of the students, regardless of gender, to understand that they actually had to explicitly document their oil removal procedures. Next, students began their scale model oil removals. To simulate the added pressure of time as a constraint, student groups were required to time how long it took them to remove all of the oil from their scale model. In order to stress the importance of efficiency, students were required to measure the amount of oil and water remaining in their scale model after the completion of their oil removal. Using the knowledge from their first attempt, student groups were then required to modify their oil removal plan, implement it, and finally evaluate its effectiveness.

During the third day of the activity, student groups worked together to answer questions relating their scale model experience to real world oil spills and the issues that might arise. In addition, students completed two mathematics problems that used the scale model volume of oil to predict a "real-world" quantity. For the remainder of the activity, students worked individually on a reading activity concerning oil spills and real-world remediation techniques. In addition, students answered application questions allowing the students to demonstrate their knowledge of water pollution and oil spills. This exercise also provided the students with an opportunity to express their opinions and write creatively. The individual completion of the questions was definitely a struggle for the students.

Figure 7 shows the average scores for each gender across all classes. As shown in this figure, female students outperformed the male students on the overall project. As in the mathematics lessons, the mixed-groups outperformed the all-male groups (see Figure 8). It was interesting to observe the behavior of the male students in this activity. Typically, groups containing male students were more eager to perform the physical construction the oil filters. 
When one group experienced a minor "oil filter explosion", they simply laughed and started to rebuild. Conversely, female students demonstrated a more deliberate design of the filter and selection of materials.

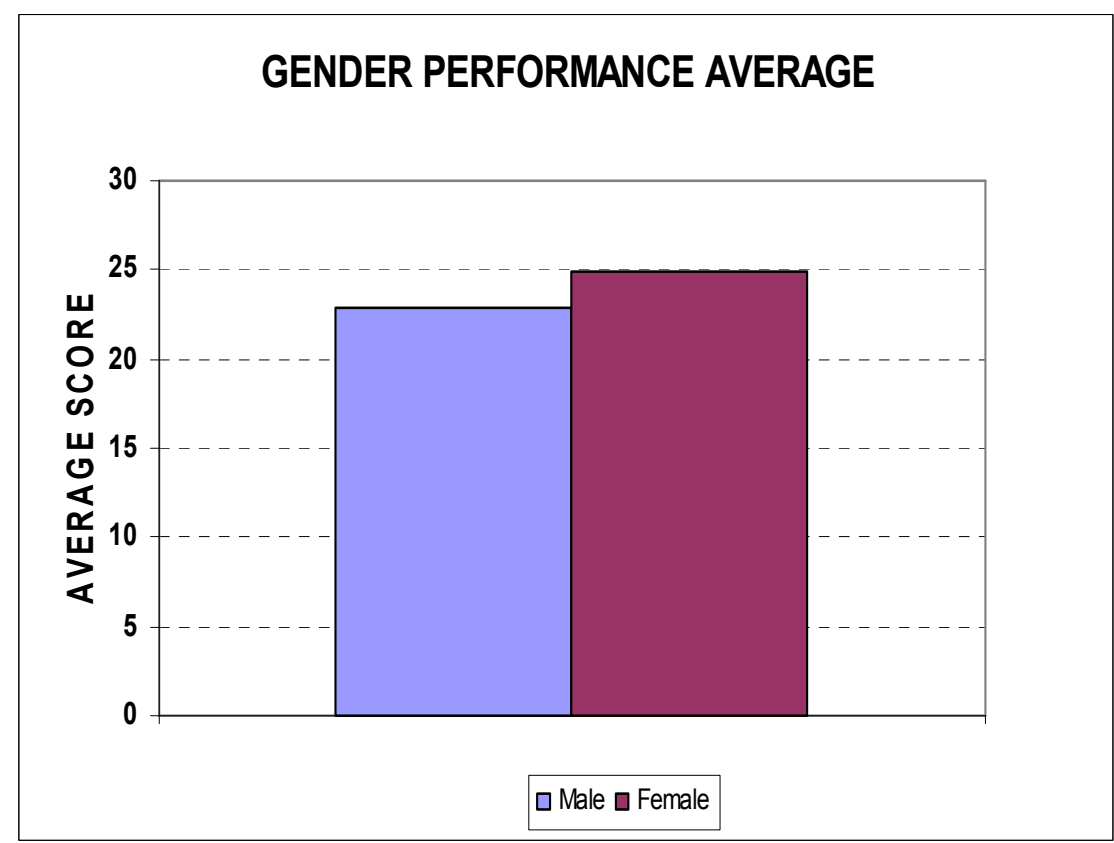

Figure 7: Gender Assessment Average for Bengal's Oily Mess

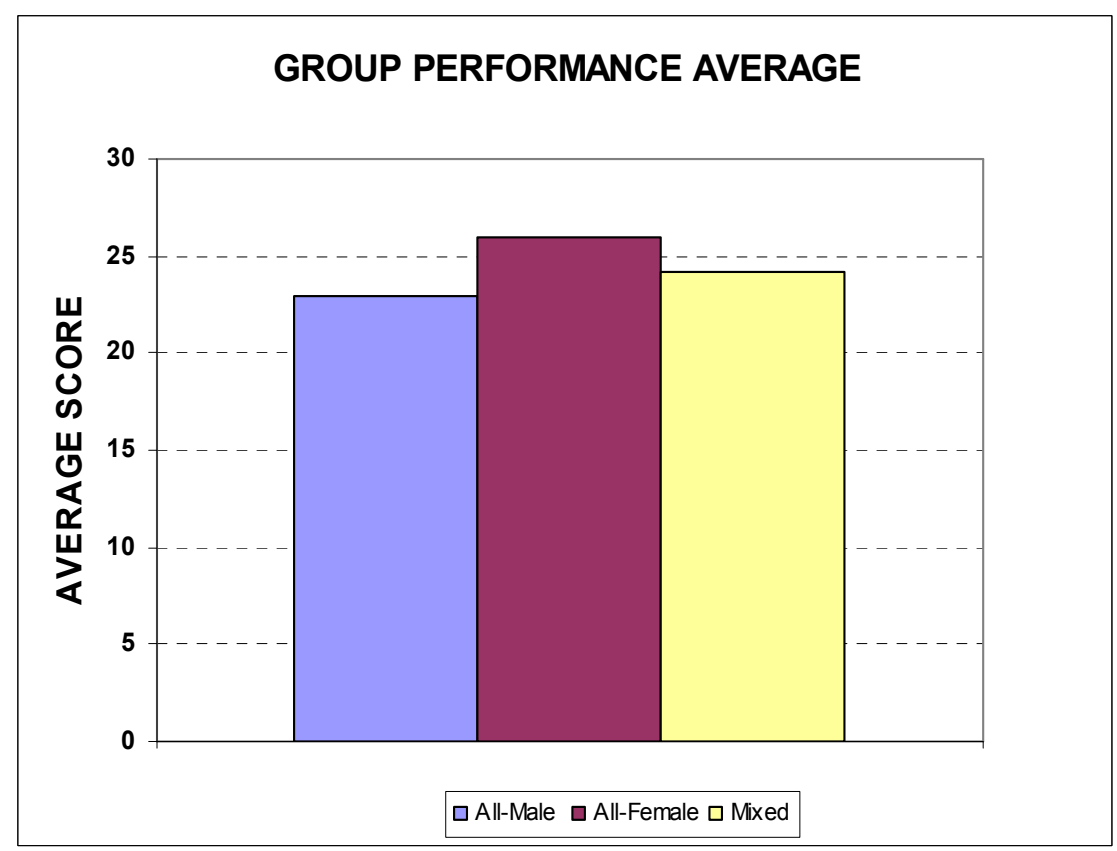

Figure 8: Gender Assessment Average for Bengal's Oily Mess

\section{Conclusions and Recommendations}


Each of the four group-based activities were designed to help investigate the effects of group makeup with respect to lesson type. Based on the statistics of these lessons, several observations are made.

Female students repeatedly outperformed male students in many of the evaluation categories. Although the exact reason for this is not entirely known, based on classroom observations and student behavior, the authors feel that female students appeared more focused on completing the activities, regardless of the subject content. However, without examining the overall performance of all the students in their school work (including non-mathematics and nonscience courses), the possibility of this particular group of female students consistently outperforming this particular group of male students cannot be ruled out.

Mixed groups resulted in higher group averages than for all-male groups in many of the key evaluation areas. In $75 \%$ of the Algebra II classes, mixed-groups also resulted in higher overall group averages than for all-female groups. In the majority of the mathematics evaluation sections, all-male groups also outperformed all-female groups.

Male students were more eager to participate in the messy and hands-on activities such as Bengal's Oily Mess than their female counterparts. Male students were also more active in the discussions of disasters and their impact in Cincinnati whereas female students demonstrated more awareness of social and human-related issues. Male students also appeared to be more focused on entertainment and sports themes within lessons.

Gender based factors that affect student learning include subjects that appeal to the students. Based on the limited sample size of these classes, the authors feel that creating lessons that have a unique hands-on activity can increase the interest of both male and female students, particularly when male and female students are paired together. Free design type activities such as the BOM and CP lessons were also more engaging, based on discussions and observations made during the exercise.

In conclusion, the formation of mixed groups appeared to significantly improve the male students' overall performance and in most cases did not significantly decrease the female students' performance. From this data, it appears that educators can improve the individual performance of male and female students as well as overall group average scores. However, to be fully conclusive, additional studies should be undertaken in additional classrooms across multiple grade levels. However, based on the results of this study, it was seen that factors such as lesson type (didactic vs. experimental), subject content (environmental / social vs. entertainment), and group makeup (individual vs. mixed group), can significantly improve the engagement level of both male and female students. As a result, when students become more engaged, they will inherently perform better in the classroom.

\section{Acknowledgements}

The authors wish to extend their appreciation to the following people and organizations for their assistance in this project:

- University of Cincinnati's Project STEP team. 
- Shroder Paideia Academy and Cincinnati Public Schools.

- Mrs. Kelly Poulin, Mathematics teacher.

- Mr. Harry Voll, Environmental Science teacher.

The "Project STEP - Science and Technology Enhancement Program" was funded by NSF's GK-12 Fellows grant (NSF-0139312) for \$1,507,500 from 5/1/02-4/30/06.

\section{Bibliography:}

1. Kahle, J.B. (2004), "Will Girls Be Left Behind? Gender Differences and Accountability", Journal of Research in Science Teaching, Vol. 41, No. 10, PP 961-969.

2. Benbow, C.P, \& Stanley, J.C. (1980)., "Sex difference in mathematical ability: Fact or artifact?”, Science, \#210, PP 1262-1264.

3. Kondrick, L.C. (2003), "What Does Literature Say about the Persistence of Women with Career Goals in Physical Science, Technology, Engineering, and Mathematics?", Paper presented at the Annual Meeting of the MidSouth Educational Research Association, (Biloxi, MS, November 5-7, 2003).

4. Kondrick, L.C. (2002),, "Understanding the Conditions that Encourage the Persistence of Women in Science, Mathematics, and Engineering Career pathways.", Unpublished doctoral dissertation, University of Arkansas Little Rock. 